\title{
Delivering safe geological disposal of nuclear waste in the UK
}

1 Cherry Tweed PhD, FGS

Chief Scientific Advisor, Radioactive Waste Management Limited, Didcot, UK

2 Alun Ellis MA, CEng, FIMechE, MNucl, MIET, MloD Science and Technology Director, Radioactive Waste Management Limited, Didcot, UK
3 Rob Whittleston PhD, FGS

Research Manager, Radioactive Waste Management Limited, Didcot, UK
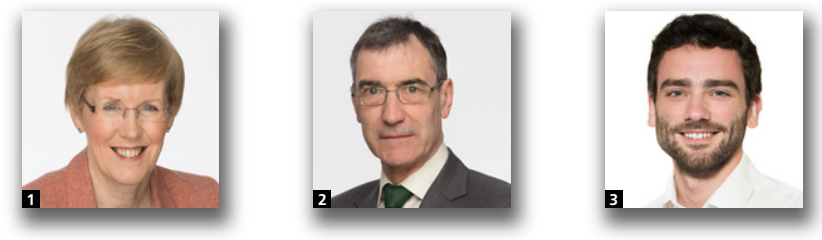

This paper discusses Radioactive Waste Management Limited's plans for implementing UK government policy for the safe geological disposal of UK's higher-activity radioactive waste. As a pioneer of nuclear technology, the UK has accumulated a diverse legacy of higher-activity radioactive waste. The paper provides a brief history of the project to date and key developments to be expected in the coming years. The paper gives an overview of the safety of geological disposal, and provides examples of the approach to ensure confidence in safety during the transport, operational and post-closure phases. It discusses the challenges in the design, construction and operation of a project with a lifetime of more than 100 years. Finally, the paper considers commonalities between the UK project and international experiences in this topic.

\section{Introduction}

As a pioneer of nuclear technology, the UK has accumulated a substantial legacy of higher-activity radioactive waste (HAW), as defined in Section 2. Some of it already exists as waste for final disposal and is being stored at nuclear sites across the UK. However, much of it will only become waste over the next century or so, as existing operational facilities reach the end of their lifetime and are decommissioned and cleaned up safely and securely.

There have been several attempts to deal with UK's HAWs. The most recent was started in 2001 when the UK government and devolved administrations initiated the Managing Radioactive Waste Safely (MRWS) programme (Defra, 2001), with the aim of addressing radioactive waste management in the long term. Government appointed a range of independent experts to a Committee on Radioactive Waste Management (CoRWM) to make recommendations that were not only provided for safety and security, but which will do so in a way that will be acceptable on environmental and societal grounds, and at a cost that was not disproportionate.

In July 2006, CoRWM recommended that, in line with international best practice, geological disposal, coupled with safe and secure interim storage, and supported by a programme of research and development, was the best available approach for the long-term management of UK's legacy of HAWs (CoRWM, 2006). The committee also recommended adoption of another widespread international approach that site selection should be based on voluntarism and partnership - that is, a community volunteering to take part in the siting process. Government and the devolved administrations published a response broadly accepting CoRWM's recommendations, and giving responsibility for the implementation of geological disposal to the Nuclear Decommissioning Authority (NDA). Following consultation the government published the MRWS white paper, A framework for implementing geological disposal, in June 2008 (Defra, 2008). The NDA subsequently established a wholly owned subsidiary, Radioactive 
Waste Management Limited (RWM) as its dedicated implementer.

CoRWM recommended that developments in alternative management options should be pursued, which RWM does through monitoring of, and participation in, national and international research and development programmes.

The MRWS white paper applied to England, Wales and Northern Ireland. The Scottish government withdrew from MRWS indicating that its policy requires the management of HAW in near-surface facilities close to the site of production. It published its own radioactive waste management policy in 2011 which states that 'it does not support deep geological disposal of radioactive waste as it does not consider it to be a "reasonable alternative" at this point in time' (The Scottish Government, 2011: p. 4). Waste that is unsuitable for nearsurface disposal (i.e. HAW) will, therefore, be subject to longterm storage.

In parallel with the publication of the 2008 MRWS white paper, the UK government invited communities to open, without commitment, discussions on possible future hosting of a geological disposal facility (GDF). In 2008-2009, three formal expressions of interest were received by the UK government - from Allerdale Borough Council, Copeland Borough Council and Cumbria County Council (in respect of the areas of Allerdale Borough Council and Copeland Borough Council).

Councils in West Cumbria proceeded through part of the staged process described in the white paper, reaching the point at which a formal 'decision to participate' was required to progress further. They formed the West Cumbria MRWS Partnership which operated for around 3 years. As part of their work they held meetings in public, set up a website on which they posted all the information they collected, including their final report, and undertook a range of engagement activities (West Cumbria MRWS, 2012).

On 30 January 2013, councils in West Cumbria took their individual decisions on whether to participate in the next stage of the siting process. Allerdale Borough Council (2013) and Copeland Borough Council (2013) both voted in favour of the proceeding. Cumbria County Council voted against (Cumbria County Council, 2013), bringing to a close the siting process in West Cumbria.

Following this decision not to participate further in the process, the UK government considered what lessons could be learned from the operation of the siting process since 2008, building on discussions with those that have been involved so far. To support this consideration, in May 2013, the UK government announced a 'call for evidence' (DECC, 2013) to allow a wider range of stakeholders to input to its review of the siting process and how it could be taken forward. After receiving responses from this, and a period of further consultation, the UK government published a new white paper in July 2014 which outlines a new policy for implementing geological disposal (DECC, 2014a). Further details of this process and the policy itself can be found in Section 6. Section 2 of this paper provides details of the wastes for disposal. A description of the concept of geological disposal and discussion as to why it is safe can be found in Section 3. Considerations for the design of a GDF, including concept, waste packages, surface and underground facilities, and challenges faced are then discussed in Section 4. Details of the approach to safety studies are given in Section 5, including those important during transport and operation, and ensuring long-term environmental safety once the facility is closed. The paper provides information on how a UK site is to be selected, Section 6, and finally introduces the international position on geological disposal.

\section{What are the wastes for disposal?}

HAWs (i.e. wastes that are not suitable for management using existing facilities such as the Low Level Waste Repository in Cumbria) are classified as wastes having a radioactive content exceeding $4 \mathrm{GBq} / \mathrm{t}$ (gigabecquerels) of alpha, or $12 \mathrm{GBq} / \mathrm{t}$ of beta/gamma activity. They are produced as a result of a number of activities. These include the generation of electricity in nuclear power stations, the associated production and processing of the nuclear fuel, the use of radioactive materials in industry, medicine and research, and from defence-related nuclear programmes.

As stated in the 2014 UK government white paper (DECC, 2014a), the specific types of HAWs (and nuclear materials that could be declared as waste) which would comprise the inventory for disposal in a GDF are

high-level waste (HLW) arising from the reprocessing of spent nuclear fuel at Sellafield

- intermediate-level waste (ILW) arising from existing nuclear licensed sites, and defence, medical, industrial, research and educational activities

- the small proportion of low-level waste (LLW) that is not suitable for disposal in the national Low Level Waste Repository

- spent fuel from existing commercial reactors (yet to be declared waste) and research reactors that is not reprocessed

- spent fuel (yet to be declared waste) and ILW from a newbuild programme up to a defined amount; currently the stated industry ambition for new nuclear development is $16 \mathrm{GW}$ electrical 
- plutonium stocks - residual plutonium that is not suitable to be reused in new fuel manufacture (yet to be declared waste)

uranium stocks - including that arising from enrichment and fuel fabrication activities (yet to be declared waste).

On the basis of the 2013 UK Radioactive Waste Inventory and other supporting information, the current estimated volume of all the waste and materials is around $650000 \mathrm{~m}^{3}$. This volume would fill just over half of Wembley stadium (57\%).

Further descriptions of the waste can be found in the 2014 white paper, Implementing Geological Disposal (DECC, 2014a), and regularly updated inventory information is maintained on the NDA's dedicated inventory website (NDA, 2014a).

\section{What is geological disposal?}

Geological disposal isolates radioactive wastes from the surface environment and contains the radioactivity so that no harmful quantities reach the surface environment. This is achieved by designing a facility with multiple engineered and natural barriers which provide 'defence in depth' and which work together to provide protection over hundreds of thousands of years. Placing this facility in rock that has been stable over lengthy geological time periods provides a high degree of assurance that the selected geological setting will continue to isolate and contain the radioactivity for long periods into the future (Chapman and McKinley, 1987; Ojovan and Lee, 2013).

The barriers that will be chosen to provide safety for geological waste disposal will be a combination of the man-made barriers provided by the waste packaging and engineered structures, and the natural barrier provided by the host geological environment. Typical man-made barriers in the safety system provided by the engineered features of the facility include

- measures taken to immobilise the waste

- robust long-lasting containers

- backfill and buffer materials around the containers

- the engineered disposal facility structure.

The natural barrier is provided by the geological setting, which will be chosen to provide containment, by - for example

- low groundwater flow

appropriate groundwater chemistry

minerals that react with radioactive species to slow down their movement

- long flow paths back to the surface environment.

The relative importance of the various barriers will depend on the chosen site and will change over time. For example for ILW, the containment by the waste container will be important during the operational period and in the early years after closure, whereas the geological barrier will take on increasing importance in the long-term, recognising that the engineered barriers cannot be guaranteed to provide containment over geological timescales. Unlike other types of hazardous materials, radioactive elements will decay and disappear over time with the majority of radioactivity decaying within the first few hundred years when the engineered barrier system is still intact.

The development of a facility for disposal of the UK radioactive waste will be taken forward within the well-established and mature regulatory framework that is used to give confidence in the safety of all civil nuclear facilities in the UK. Safety arguments will have to be presented for every aspect of the proposed facility, covering getting waste to the facility, construction and operation, and safety in the long-term following sealing and closure. The safety case will be based on demonstrating understanding of the behaviour and evolution of the various barriers, both the man-made and natural ones and the safety functions that they will be providing. More details on the regulatory approach to geological disposal can be found on the Office for Nuclear Regulation (ONR) website (ONR, 2014).

An important step in the development of the facility is the site investigation programme, which establishes an understanding of the characteristics of the site, including structural geology, hydrogeology and hydrochemistry. This will be achieved through a comprehensive programme of non-intrusive and intrusive investigation techniques including using deep borehole drilling.

Construction methods and operational regimes will be defined in such a way as to give confidence that the safety requirements are delivered in practice. This may mean, for instance, that construction techniques are specified that will minimise the 'excavation damage zone' and that boreholes are sealed to a standard that precludes future fast groundwater return to the surface. Further discussion of studies that have been carried out to provide confidence in safety is given in Section 5 .

\section{Designing a GDF}

\subsection{The concepts}

A GDF will be a highly engineered facility, comprising both surface and underground facilities.

Generic illustrative designs have been developed in three generic host geological environments that occur in the UK and are considered potentially suitable to host such a facility. The rock types are classified as higher-strength rocks, lowerstrength sedimentary rocks and evaporites. The illustrative designs are derived from a number of mature concepts developed by other waste management organisations. These 
concepts are supported by extensively documented research and development, and have been subject to detailed safety assessment, regulatory scrutiny and international peer review. Table 1 shows the sources of RWM's illustrative geological disposal concepts for the three generic host geological environments under consideration.

As a GDF will be funded by central government, there is a government mandate for the project to be level 2 building information modelling (BIM) compliant by 2016. In order to meet this requirement, work on the project is now undertaken in a BIM environment, and the corresponding BIM strategy has been published by RWM (NDA, 2013b).

Implementing a GDF in the UK is a unique project with a multi-billion pound budget and a project lifetime of more than 100 years. The GDF project will provide up to 1000 jobs during the initial construction phase, and over the entire operational period there will be an average of more than 550 jobs (NDA, 2012).

Integrating safety within design is vital to ensure the safety of a GDF and is addressed through the application of safety functional requirements, which provide a formal auditable link between the safety assessment and the design. In addition to safety functional requirements for the near term (i.e. during construction and operation), there are also long-term safety requirements that must be met once the GDF enters the postclosure phase. These requirements are embodied into the design through the disposal system specification, which RWM has published (NDA, 2010a).

To meet government targets on sustainable development, a number of sustainable design objectives have been developed, derived from the project's design principles, to help avoid or minimise long-term damage to the natural environment, make the most of opportunities for environmental improvement, and to support the social and economic needs of a host community. The sustainable design objectives, published by RWM, will be taken into consideration throughout the design process (NDA, 2010b). As part of the sustainable design objectives, the environmental and visual impact of a GDF will need to be considered in order to mitigate any unnecessary impacts. This is expected to include, for example, constructing surface landscaping bunds from the excavated spoil to reduce the visual and noise impacts of the surface facilities (Figure 1).

\subsection{Packaging the waste}

Radioactive wastes need to be packaged into a passively safe state, in which they can be safely handled and stored, as soon as reasonably practicable, prior to a GDF being available.

Illustrative geological disposal concept examples ${ }^{a}$

Host rock

Higher-strength rocks ${ }^{b}$

Lower-strength sedimentary rocks ${ }^{c}$

Evaporites $^{d}$
ILW/LLW HLW/SF

UK ILW/LLW concept (NDA, UK)

Opalinus clay concept (Nagra, Switzerland)

WIPP bedded salt concept (US-DOE, USA)
KBS-3V concept (SKB, Sweden)

Opalinus clay concept (Nagra, Switzerland)

Gorleben salt dome concept (DBE-Technology, Germany)

${ }^{a}$ For planning purposes, the illustrative concept for depleted, natural and low-enriched uranium (DNLEU) is assumed to be same as for ILW/LLW and for plutonium and highly enriched uranium is assumed to be the same as for HLW/SF

${ }^{b}$ Higher-strength rocks - the UK ILW/LLW concept and KBS-3V concept for spent fuel were selected due to availability of information on these concepts for the UK context

CLower-strength sedimentary rocks - the Opalinus Clay concept for disposal of long-lived ILW, HLW and spent fuel was selected due to a recent OECD Nuclear Energy Agency review regarded the Nagra (Switzerland) assessment of the concept as state of the art with respect to the level of knowledge available. However, it should be noted that there is similarly extensive information available for a concept that has been developed for implementation in Callovo-Oxfordian Clay by Andra (France), and which has also been accorded strong endorsement from international peer review. Although the authors will use the Opalinus Clay concept as the basis of the illustrative example, they will also draw on information from the Andra programme. In addition, they will draw on information from the Belgian supercontainer concept, based on disposal of HLW and spent fuel in Boom Clay

${ }^{\mathrm{d}}$ Evaporites - the concept for the disposal of transuranic wastes (long-lived ILW) in a bedded salt host rock at the Waste Isolation Pilot Plant (WIPP) in New Mexico was selected due to the wealth of information available from this United States Environmental Protection Agency certified, and operating facility. The concept for disposal of HLW and spent fuel in a salt dome host rock developed by DBE Technology (Germany) was selected due to the level of concept information available

Table 1. Sources of illustrative geological disposal concepts for

host environments and classes of waste (NDA, 2010c) 


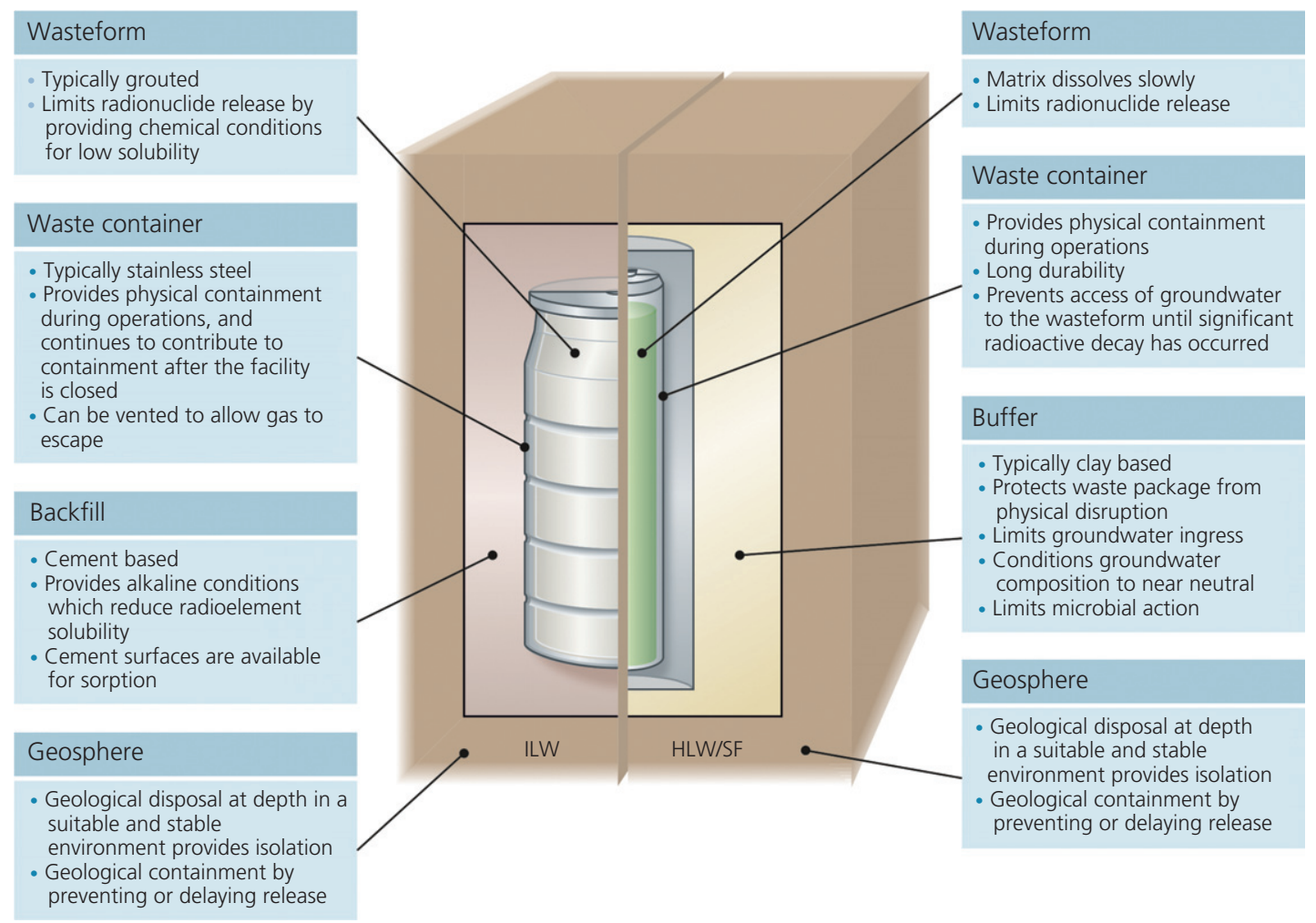

Figure 1. Multi-barrier approach - illustration of key components (adapted from NDA, 2010c)

Radioactive wastes are conditioned and packaged into a variety of robust packages (see Figure 2), depending on the type of waste, prior to their dispatch to a GDF. When a GDF becomes available, the majority of packaged wastes will be transported from stores to a GDF, in a shielded transport container, such as the standardised waste transport container (SWTC) (see Figure 3), to ensure that any dose to the public is safe within the regulations. To ensure that waste that is packaged today will be safe and suitable for disposal in a GDF, assessments of packaging proposals are undertaken by RWM, as part of the letter of compliance disposability assessment process, which is carried out against published waste package specifications (NDA, 2014b). However, this assessment does not remove the need for further assessment of the waste package against future site-specific waste acceptance criteria.

\subsection{Surface facilities}

The GDF surface facilities will cover $\sim 1 \mathrm{~km}^{2}$ (which is about two-thirds of the surface area of the proposed Hinkley Point $\mathrm{C}$ nuclear site), and have the appearance of a secure industrial complex. Figure 4 is an aerial view of a generic GDF surface layout (i.e. not tailored to any particular surface site). The

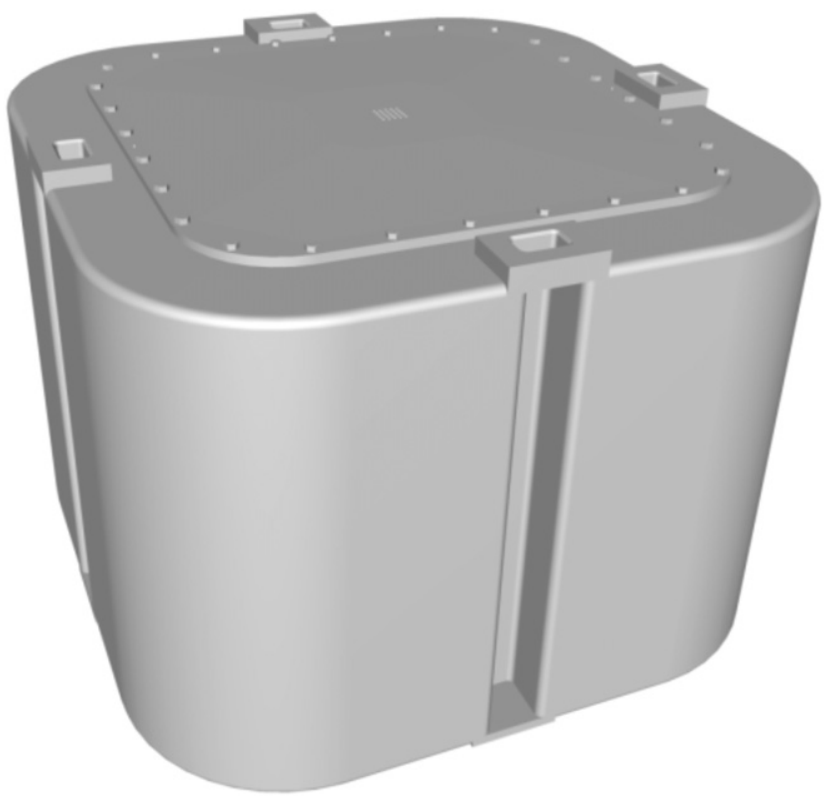

Figure 2. An unshielded $3 \mathrm{~m}^{3}$ box for decommissioning and retrieved wastes (NDA, 2010g) 
Energy

Volume 168 Issue EN4
Delivering safe geological disposal of

nuclear waste in the UK

Tweed, Ellis and Whittleston

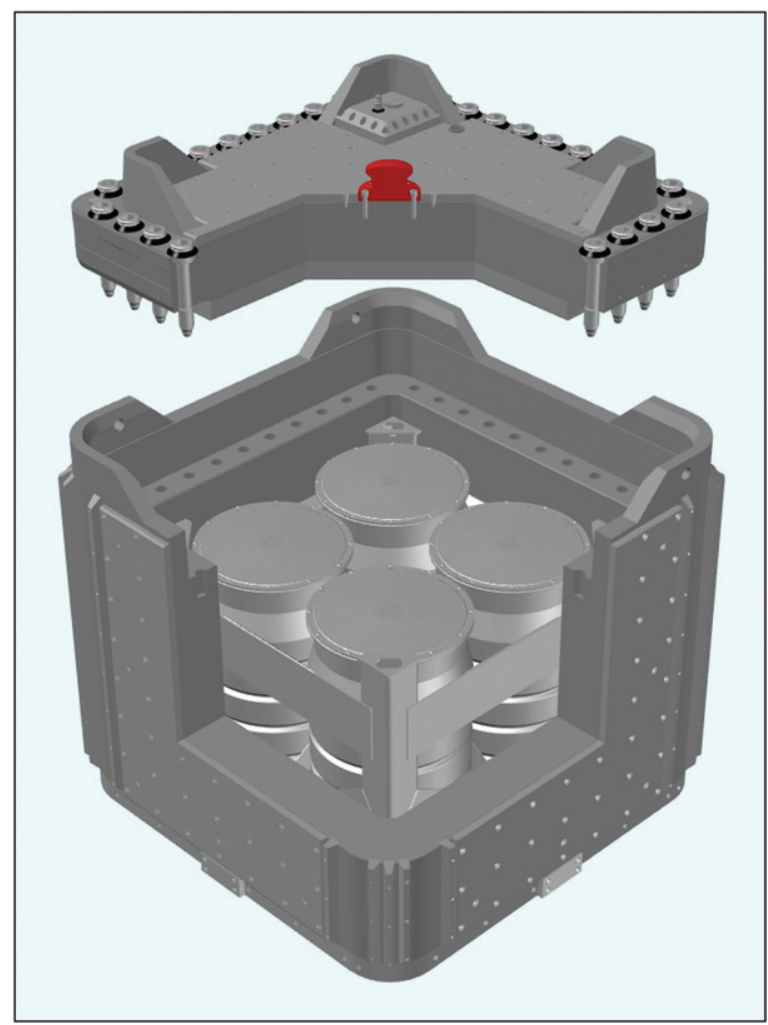

Figure 3. A shielded waste transport container for ILW and depleted, natural and low-enriched uranium (DNLEU) (NDA, 2010g) primary purpose of the surface facilities is to receive waste packages from the national rail and road network and transfer them to the underground disposal facility.

It is currently planned that there will be four access routes between the surface and underground - for example, comprising one inclined tunnel, called a 'drift' and three or four vertical shafts. These provide security of access and egress, separation of construction and waste disposal operations, and separate ventilation systems for waste disposal operations and the construction areas that are planned to occur in parallel. There will be buildings to support ongoing underground construction, including the receipt of construction materials and the dispatch of excavated material. The spoil will be managed as landscaping bunds on the surface, reused as backfill material underground or transported off-site.

Some surface buildings will support underground construction (shaft and drift excavation) and preparation activities associated with development of surface facilities - for example, soil stripping, services and landscaping. Buildings to support waste receipt will be built to the necessary safety and security standards. Other facilities to support construction and receipt of waste include infrastructure such as railway sidings, roads and car parks, maintenance and essential services, administration offices and operational control rooms.

Layout of the surface site will be dictated by site-specific factors such as topography, available space and availability of

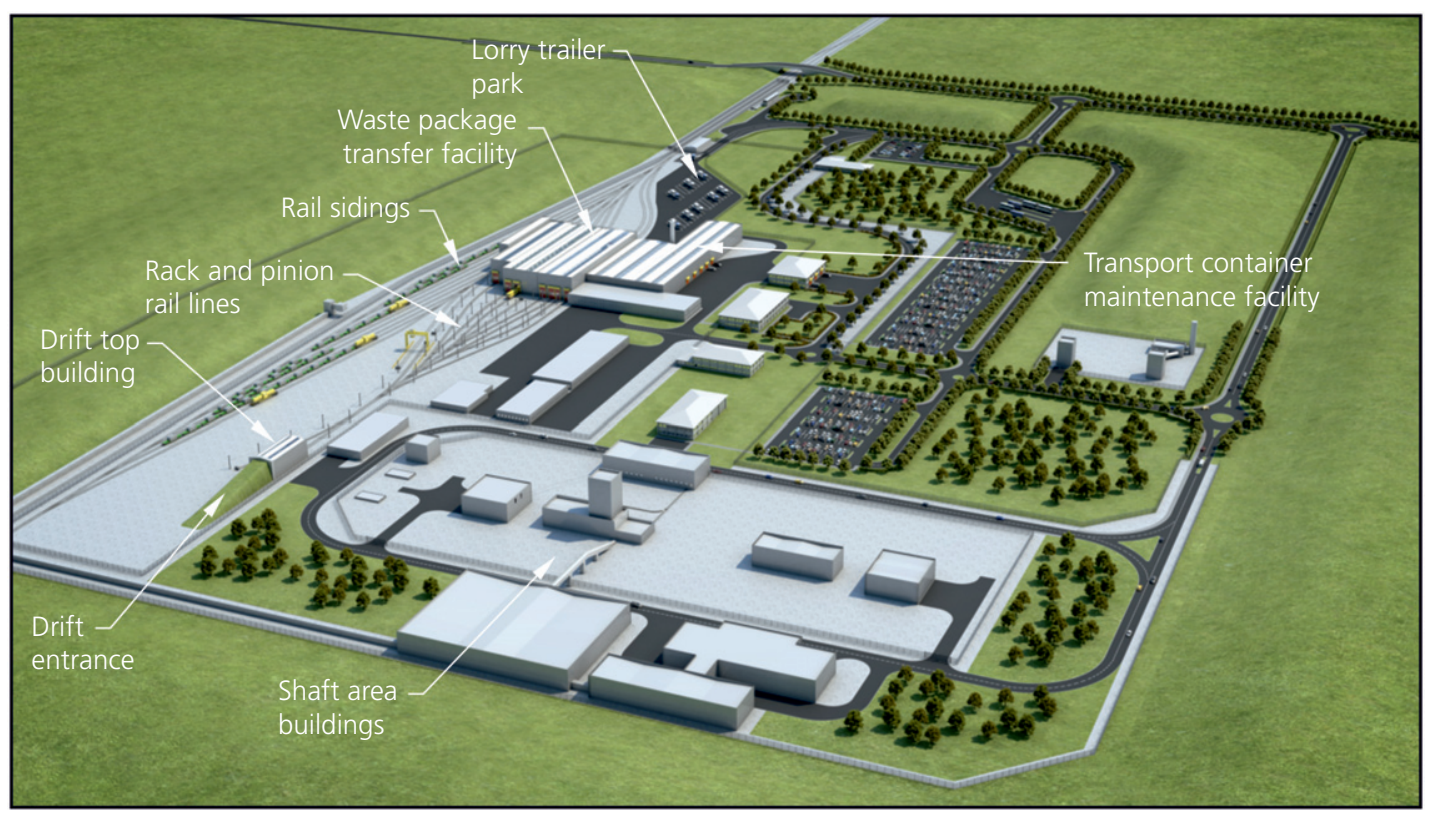

Figure 4. Illustrative geological disposal facility surface layout 
Energy

Volume 168 Issue EN4
Delivering safe geological disposal of

nuclear waste in the UK

Tweed, Ellis and Whittleston existing infrastructure. It will be important to work with potential host communities to develop the designs and layouts of the surface facilities to ensure they are sympathetic to the local environment (NDA, 2010c)

\subsection{Underground facilities}

The illustrative designs used for planning purposes are based on the assumption of a single underground facility to accommodate all the wastes and materials in the Radioactive Waste Inventory, as outlined in the 2014 white paper (DECC, 2014a). Figure 5 illustrates two disposal areas at a depth of between 200 and $1000 \mathrm{~m}$ (the actual depth of the facility is dependent on site and geology), separated by an appropriate distance to prevent interaction. One disposal area comprises a system of vaults for the disposal of ILW and some LLW and the other an area of disposal tunnels with deposition holes for
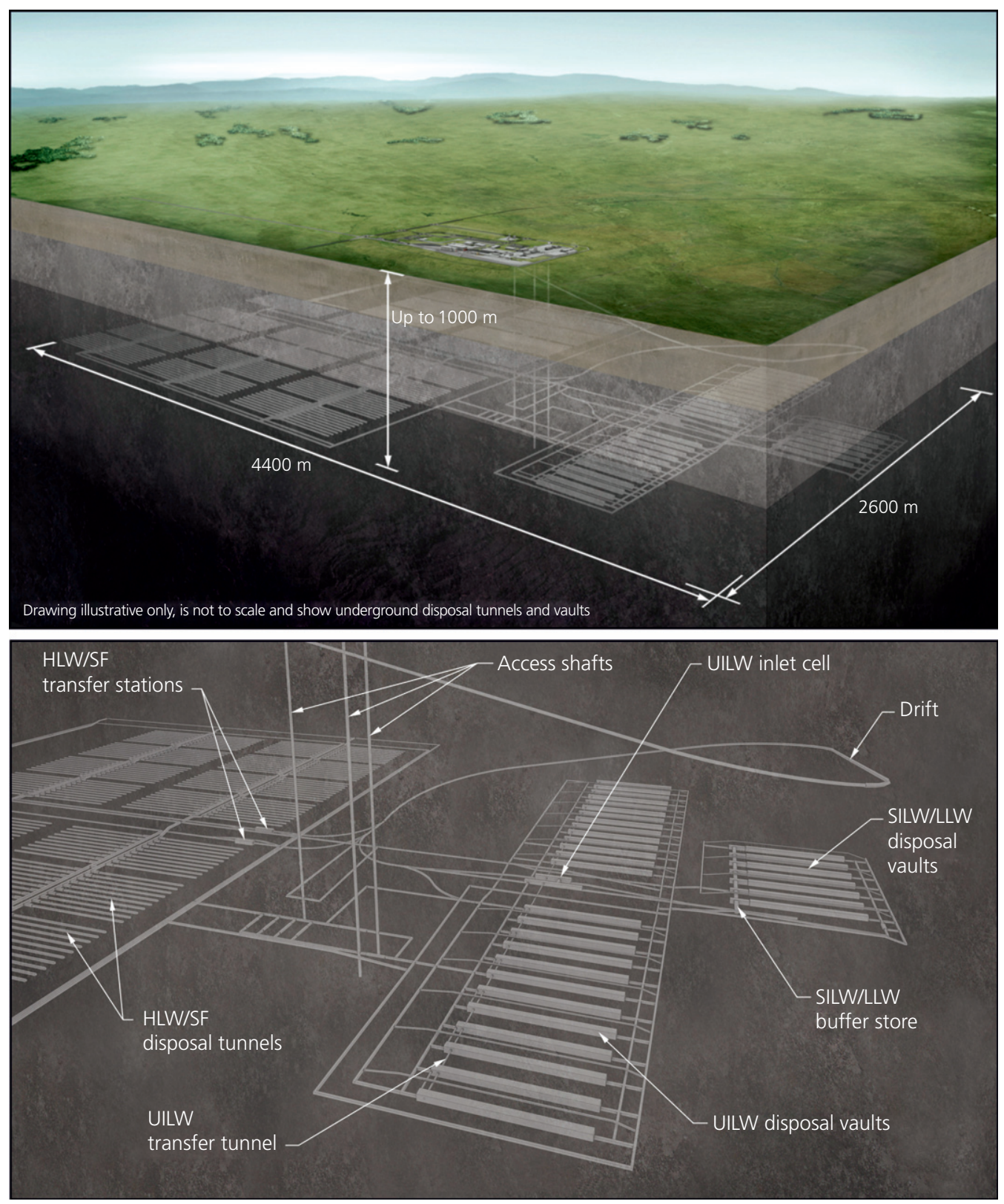

Figure 5. Illustrative geological disposal facility underground layout 
wastes such as HLW or spent fuel, which emit significant amounts of heat.

For a waste inventory that includes nuclear materials and newbuild wastes including spent fuel, the underground facilities will cover a footprint of $\sim 10 \mathrm{~km}^{2}$ in higher-strength rocks, and up to $20 \mathrm{~km}^{2}$ in lower-strength rocks and evaporites. For comparison, the recently closed coal mine, Daw Mill, near Coventry had a footprint of around $26 \mathrm{~km}^{2}$. The total excavated volume is $\sim 14000000 \mathrm{~m}^{3}$ in higher-strength rocks and $12000000 \mathrm{~m}^{3}$ in lower-strength rocks and evaporite rocks (NDA, 2010c).

The underground disposal areas are currently assumed to be located beneath the surface facilities, although if site-specific constraints dictated, it would be possible to locate the surface facilities remote to the underground disposal areas and connect these by way of underground tunnels. At the current illustrative design stage, a practical separation limit of around $10 \mathrm{~km}$ has been assumed. A geological disposal facility will be engineered to deliver safety and security, through a combination of established construction techniques such as drilling and blasting methods, tunnel-boring machines and road headers, with the choice of technique being dependent on the nature and properties of the host rock, and consideration of the effects of the construction techniques on worker, operational and long-term safety. The underground excavations will be of varying sizes and cross-sections, depending on the rock strength but it is likely that these will range from $2.5 \mathrm{~m}$ dia. for disposal tunnels in lower-strength rocks to $16 \mathrm{~m} \times 16 \mathrm{~m}$ for the largest vaults in higher-strength rocks. In the current illustrative designs, the access shafts are $8 \mathrm{~m}$ in diameter and excavated using established shaft-sinking technologies. The inclined drift access is assumed to be $5.5 \mathrm{~m}$ in diameter and would be equipped with a rack-and-pinion rail system capable of transferring waste packages of up to $65 \mathrm{t}$ gross mass down a gradient of 1 in 6 and at a throughput rate of c. 4000 waste packages annually. At specific sites, it may not be possible to provide drift access, in which case shaft access would be used for transporting the wastes underground. More detailed information on the current generic illustrative designs can be found in NDA (2010c).

\subsection{Design challenges}

The current illustrative designs demonstrate confidence in the ability to construct a viable GDF in the UK to accept the UK's radioactive waste inventory for disposal. The illustrative designs are based on a number of internationally recognised, technically feasible, concepts which have been internationally peer reviewed and have been subject to regulatory scrutiny.

Designing, constructing and operating a GDF in the UK poses a number of challenges that are currently being addressed. To ensure that a GDF can contain and isolate radioactive waste, it is important to ensure that the excavated damage zone (EDZ) is minimised, so as not to create any preferential pathways for radionuclide migration from the GDF to the surface. The extent of any EDZ around an excavation will depend on a number of factors, including hydrogeological and mechanical properties of the strata, the state of the in situ stress, and the size and geometry of the opening and the excavation methods used. The timing and rigidity of the support will also have an impact on the development of the EDZ.

Concurrent operations will allow the 'just in time' principle to be applied, which will ensure that the disposal vaults/tunnels are excavated and the waste emplaced in a timely manner to ensure the integrity of the excavations. This poses a number of challenges as it assumes that the underground construction would be kept separate from the disposal activities by the use of separate access routes underground, separate ventilation circuits and a series of bulkheads and seals. Ongoing underground construction would allow continuous geotechnical mapping and inspection to be undertaken to allow tailoring of the design to incorporate site-specific geological characteristics and apply lessons learnt with regard to construction and waste emplacement techniques.

A GDF will be fitted out with systems to ensure that the required operations can be carried out in a safe manner. As previously discussed, due to the long operational timescale, a robust maintenance schedule will be required. The long operational timescale also poses the issue of obsolescence, which has affected many parts of the nuclear industry and will thus have to be factored into the design through future-proofing.

A number of challenges also arise from operating a GDF at a depth of between 200 and $1000 \mathrm{~m}$. The underground environment must be controlled to ensure that the safety functional requirements can be met including the management of groundwater inflow during the construction and operation of a GDF and as a number of waste packages will release gases, there must be sufficient ventilation during the construction and operation phases to ensure the safety of workers and the public.

\section{What safety studies have been conducted so far?}

RWM and its precursor organisations have been examining the scientific basis for geological disposal for more than 25 years and periodically have published scientific updates and safety studies. The most recent of these, the generic disposal system safety case (DSSC) was published in 2010. This is a significant study comprising some 30 individual reports describing the state of the art for geological disposal design and safety and supporting scientific evidence base.

The document suite has been well received by regulators and stakeholders as it brings together for the first time integrated 
designs and assessments for the full range of waste types that will, or may, require geological disposal as discussed earlier. It is termed 'generic' as it follows a process that avoids making siting assumptions in the design or supporting materials and shows, by way of illustrative examples, what the facility might look like in different geological settings that could be utilised for a GDF in the UK. Furthermore, generic safety assessments are used to investigate the safety issues associated with transporting the range of wastes to such a facility, the safety issues associated with the operations (i.e. waste receipt, transfer underground, emplacement, decommissioning and closure) and finally environmental safety considerations in the long term as discussed earlier, in the period after the facility has been closed and the various barriers, both the engineered ones and the natural ones, come into play.

\subsection{Transport}

The transport system required to move the existing and future stocks of radioactive waste to a GDF will be a significant operation. Planning studies have considered the logistical and safety issues and have reported on the outcomes in the transport safety case (NDA, 2010d), one of the components of the generic DSSC. Legislation governing radioactive materials transport in the UK is based on safety standards developed and promulgated by the International Atomic Energy Agency. The transport safety case demonstrates that the transport operation, together with the transport package designs proposed, should meet the high standards of safety specified. The assessment identifies how to address safety for road, rail and sea transports, depending on what is required for an eventual GDF site. In line with normal safety case methods, the assessments have been used to identify uncertainties and where further information or research would be beneficial. In the transport studies, it has been shown that dose uptake by transport workers would be high without additional steps to reduce dose uptake by introducing additional shielding or by automating key activities.

\subsection{Operations}

Geological disposal is expected to be a licensable activity as defined by the Nuclear Installations Act 1965 (1965) and therefore the requirements to meet licence obligations are clearly defined by the regulator in this area, the ONR. The operational safety case (OSC) (NDA, 2010e) and supporting documents within the DSSC have been structured to address the key nuclear safety considerations at this early generic stage. Production of a generic assessment in advance of having a site and a settled design is unusual; therefore, it has been necessary to interpret ONR guidance and in some cases determine what is appropriate at this early stage. The OSC follows standard nuclear safety approaches and calculates expected doses to operators and the public from normal operations and as a result of postulated accidents involving waste packages. The assessments are used in an iterative manner to determine where design enhancements should be made to facilitate an eventual demonstration that doses have been reduced 'as low as reasonably practicable'. The OSC demonstrates how confidence can be assured that it will be possible to develop a GDF design and mode of operation that will be capable of meeting modern safety standards for nuclear facilities.

\subsection{Long-term environmental safety}

As part of the development consent for a GDF, it will have to be demonstrated to the environmental regulator (the Environment Agency in England and Wales) that there is confidence that the construction, operation and eventual closure of the facility can be undertaken successfully, while protecting the environment and people, now and into the long-term future. This will be an iterative process that requires increasing levels of confidence and evidence as the project progresses through site characterisation, construction and operation and eventually prior to the final closure stage. This evidence case is termed the environmental safety case (ESC) and GDF development will only proceed if the ESC at key stages is judged by the regulator to be sufficiently robust to move to the next stage.

The GDF development plan is not yet at a regulatory review point (the first formal stage will occur when a site has been identified, prior to starting intrusive (e.g. borehole) investigations); however, an early-stage generic ESC (NDA, 2010f) as part of the DSSC has been produced. This ESC shows how for the identified generic geological settings, the various engineered and natural barriers will work together to provide multiple barriers for the containment of radioactivity. The ESC is founded on understanding of the behaviour of the waste packages following disposal and evolution of the 'disposal system'. The generic ESC is structured around the Environment Agency guidance (EA, 2009) for an ESC despite being some way from making a formal safety case submission. This has had the advantage of ensuring that all the key issues are covered (although not in depth) and demonstrates understanding of the requirements.

\section{How will a site be selected?}

In July 2014, the UK government published a new white paper (DECC, 2014a) setting out the revised approach to siting and also a response to all the contributions received to the consultation exercise (DECC, 2014b).

This paper sets out the policy framework for the future implementation of geological disposal in the UK, including

establishing an up-front process of national screening, based on known geological information. This process will be led by the developer, drafting national screening guidance that will be evaluated by an independent review 
panel, in an open and transparent manner, before being applied across the UK (excluding Scotland)

- in England, bringing GDFs, and the borehole investigations that support their development, within the statutory definition of 'Nationally Significant Infrastructure Projects' within the Planning Act 2008 (2008). This will provide an appropriate process for planning decisions, making public consultation an integral part of this process. The UK government will develop a generic (i.e. non-sitespecific) national policy statement to support the planning process, providing the framework within which the decision to construct will be taken, and further up-front information to inform discussions with communities

- developing the process of working with communities, including

deciding on an approach to community representation, which will be informed by a community representation working group convened following publication of this white paper

- providing high-level information on community investment, including the process for deciding how and when this money will be invested, in relation to

- communities engaging in the siting process

- the community or communities that decide to host a GDF

- establishing a mechanism by which communities, the developer and government can openly access independent, third-party advice on key technical issues during the siting process.

Formal discussions between interested communities and the developer will not begin until the initial actions set out in this white paper have been completed, in around 2016.

In reviewing the siting process that operated since 2008, and taking into account responses to the consultation on the review of this process, the UK government continues to favour an approach to siting a GDF that is based on the willingness of local communities to participate in the process.

Useful lessons have been learned about how a voluntarist approach can be delivered more effectively in the future. In particular, the importance of providing up-front information, on issues such as geology, socio-economic impacts and community investment, has been highlighted. The availability of clear, evidence-based information on both technical issues and the process of working with communities, in advance of formal discussions between communities and the developer, will enable communities to engage in the process with more confidence.

This new siting process will provide more information to communities before they are asked to get involved. With greater clarity on issues such as geology and development impacts, community investment and community representation, communities will be able to engage with more confidence in the process to deliver this nationally significant infrastructure project.

The consultation responses revealed a strong desire for early consideration of geology as a crucial step in building public understanding of GDF development, and confidence in the process to identify and consider safe potential siting areas. Although it is not possible to identify sites as definitely suitable on the basis of a national, high-level consideration, there is merit in carrying out an open consideration of what could be achieved through an early screening exercise.

Therefore, the UK government has decided to ask RWM, as the developer, to carry out a national geological screening exercise based on the requirements of the existing generic GDF safety cases. This exercise will first consider openly what geological attributes should be considered in producing national, high-level screening guidance, using existing geological information and based on the requirements of the generic GDF safety cases. The high-level guidance will then be applied across the country, to bring together high-level geological information relevant to the GDF safety cases.

The developer will be expected to undertake this work in a suitably open and transparent manner, engaging the public and expert stakeholder communities from the outset in consideration of what geological attributes could and should be included in high-level screening guidance. As a developer, RWM is keen to encourage all interested parties, including engineers, to engage in this activity and has created a subscription service so that news updates can be sent to those requesting them. Please subscribe to this update service at http://www.nda.gov.uk/rwm/.

The outputs from this exercise will allow the developer to engage openly on questions about local geological prospects that are likely to be raised early in any community's thinking about possible GDF developments.

\section{What is the international position?}

Geological disposal is internationally recognised as the preferred approach for the long-term management of HAW, protecting both human health and the natural environment. The July 2011 European Union (EU) Council Directive 2011/70 Euratom establishing a community framework for the responsible and safe management of spent fuel and radioactive waste stated that 'Deep geological disposal represents the safest and most sustainable option as the end point of the management of high-level waste and spent fuels considered as waste' (EU, 2011: p. 50).

The Nuclear Energy Agency of the Organisation for Economic Co-operation and Development (OECD-NEA) assists member 
countries in maintaining and developing safe and environmentally friendly use of nuclear energy for peaceful purposes. This includes assisting the development of acceptable strategies for the management of all types of radioactive waste, through the radioactive waste management and decommissioning working group (OECD-NEA, 2014).

The EU vision is that by 2025 , the first geological disposal facilities for spent fuel, high-level waste and other long-lived radioactive waste will be operating safely in Europe. These will also be the first such facilities in the world, demonstrating the lead that Europe has in safe and responsible management of the back-end of the nuclear fuel cycle. The EU is supporting a technical programme to coordinate research into implementing geological disposal. This is called the Implementing Geological Disposal - Technical Platform (IGD-TP, 2014). This platform will coordinate and implement the necessary research and development $(\mathrm{R} \& \mathrm{D})$ to realise this objective, involving a wide range of $\mathrm{R} \& \mathrm{D}$ stakeholders involved in this field.

A number of countries have waste management plans involving deep geological disposal facilities for intermediate- and highlevel radioactive wastes and/or spent fuel. Some programmes are significantly more advanced in their implementation than the UK. For example, Sweden and Finland have submitted licence applications to construct facilities for the disposal of spent fuel at their chosen sites. The UK programme works closely with counterpart organisations around the world through a range of forums to ensure that experiences are shared and lessons learned. The experiences from overseas show a range of approaches to finding sites and seeking the involvement of local communities. Experience from around the world has shown that those programmes based on engagement with local communities continue to progress in a mutually acceptable way. Processes perceived to involve imposition on an unwilling community have failed.

An analysis of international programmes (NDA, 2013a) has shown that

the programmes in each country reflect the political and cultural circumstances in each country

- some siting processes faced setbacks in the early stages; before proceeding with a revised process

- local government is always involved as the representative of the community and, with the exception of Switzerland, has a decision-making role in the process

- the elected representatives of the community closest to where the disposal facility will be built (the local municipality) tend to be the local decision maker in the siting process

- engagement with the issues, understanding and support at a local level is often higher than it is at a regional or national level

- the benefits associated with a GDF which are made available to potential host communities vary from country to country in their approach, scope, amount and when they become available. In a number of countries, these benefits are scheduled to be made available in advance of the facility being constructed.

\section{Conclusion}

This paper has introduced geological disposal as the internationally preferred approach for dealing with HAWs. Multiple engineered and natural barriers will be used to isolate radioactive waste from the surface environment and contain the radioactivity so that no harmful quantities ever reach the earth's surface. As has been discussed, these barriers work together to provide 'defence in depth' and ensure safety over very long time periods. For any such facility, safety needs to be demonstrated to the satisfaction of the appropriate national regulatory body. The technologies for implementing geological disposal have been shown to be feasible and a number of overseas countries have implementation programmes that are well advanced.

Although the technology for geological disposal is well established, societal challenges still remain. Experience from around the world has shown that those programmes based on engagement with local communities continue to progress in a mutually acceptable way. This voluntarism approach has been adopted as government policy in the UK and detailed proposals for siting are currently being developed.

\section{REFERENCES}

Allerdale Borough Council (2013) Allerdale Borough Council Meeting Minutes, January 2013. Allerdale Borough Council, Maryport, UK. See http://democracy.allerdale. gov.uk/documents/g3743/Printed $\% 20$ minutes $\% 2030$ th-Jan2013\%2015.00\%20Executive.pdf?T=1 (accessed 26/02/2015).

Chapman N and McKinley I (1987) The Geological Disposal of Nuclear Waste, 1st edn. Wiley-Blackwell, Chichester, UK.

Copeland Borough Council (2013) Copeland Borough Council Meeting Minutes, January 2013. Copeland Borough Council, Whitehaven, UK. See http://www.copeland.gov. uk/sites/default/files/attachments/CIS/pdf/exe_300113_ minutes.pdf (accessed 26/02/2015).

CoRWM (Committee on Radioactive Waste Management) (2006) Managing our Radioactive Waste Safely: CoRWM's Recommendations to Government. Committee on Radioactive Waste Management, London, UK.

Cumbria County Council (2013) Cumbria County Council Meeting Minutes, January 2013. Cumbria County Council, Carlisle, UK. See http://councilportal.cumbria. gov.uk/documents/g7230/Printed $\% 20$ minutes $\% 2030$ th-Jan2013\%2010.00\%20Cabinet.pdf?T=1 (accessed 26/02/2015).

DECC (Department of Energy and Climate Change) (2013) Review of the Siting Process for a Geological Disposal Facility. Department of Energy and Climate Change, 
London, UK. See https://www.gov.uk/government/uploads/ system/uploads/attachment_data/file/239237/Consultation_ Review_of_the_siting_process_for_a_GDF_FINAL.pdf (accessed 19/03/2015).

DECC (2014a) Implementing Geological Disposal - A Framework for the Long-Term, Management of Higher Activity Radioactive Waste. Department of Energy and Climate Change, London, UK.

DECC (2014b) Government Response to Consultation. Department of Energy and Climate Change, London, UK. Defra (Department for Environment, Food and Rural Affairs) (2001) Managing Radioactive Waste Safely: Proposals for Developing a Policy for Managing Solid Radioactive Waste in the UK. Department for Environment Food and Rural Affairs, London, UK.

Defra (2008) Managing Radioactive Waste Safely: A Framework for Implementing Geological Disposal. Department for Environment, Food and Rural Affairs, London, UK.

EA (Environment Agency) (2009) Geological Disposal Facilities on Land for Solid Radioactive Wastes, Guidance on Requirements for Authorisation. Environment Agency, Bristol, UK.

EU (European Union) (2011) Council Directive 2011/70/ Euratom of 19 July 2011 establishing a community framework for the responsible and safe management of spent fuel and radioactive waste. Official Journal of the European Communities L199/48. See http://europa.eu/ legislation_summaries/environment/waste_management/ en0027_en.htm (accessed 19/03/2015).

IGD-TP (Implementing Geological Disposal - Technical Platform) (2014) http://www.igdtp.eu/ (accessed 26/02/2015).

NDA (Nuclear Decommissioning Authority) (2010a) Geological Disposal: An Introduction to the Disposal System Specification. Nuclear Decommissioning Authority, Cumbria, UK.

NDA (2010b) Geological Disposal: Sustainable Design Objectives for a Geological Disposal Facility. Nuclear Decommissioning Authority, Cumbria, UK.

NDA (2010c) Geological Disposal: Generic Disposal Facility Designs. Nuclear Decommissioning Authority, Cumbria, UK.

NDA (2010d) Geological Disposal: Generic Transport Safety Case Main Report. Nuclear Decommissioning Authority, Cumbria, UK.

NDA (2010e) Geological Disposal: Generic Operational Safety Case Main Report. Nuclear Decommissioning Authority, Cumbria, UK.

NDA (2010f) Geological Dsiposal: Generic Environmental Safety Case Main Report. Nuclear Decommissioning Authority, Cumbria, UK.

NDA (2010g) Geological Disposal: Generic Transport System Designs. Nuclear Decommissioning Authority, Cumbria, UK.
NDA (2012) Geological Disposal: Manpower and Skills Requirements 2012 Update. Nuclear Decommissioning Authority, Cumbria, UK.

NDA (2013a) Geological Disposal: Overview of International Siting Processes. Nuclear Decommissioning Authority, Cumbria, UK.

NDA (2013b) Geological Disposal: RWMD Building Information Management Strategy and Implementation Plan. Nuclear Decommissioning Authority, Cumbria, UK.

NDA (2014a) 2013 UK Radioactive Waste Inventory. Nuclear Decommissioning Agency, Cumbria, UK. See https:// www.nda.gov.uk/ukinventory/ (accessed 26/02/2015).

NDA (2014b) Geological Disposal: An Overview of the RWM Disposability Assessment Process. Nuclear Decommissioning Authority, Cumbria, UK. Nuclear Installations Act 1965 (1965) Elizabeth II. Chapter 57. Her Majesty's Stationery Office, London, UK.

OECD-NEA (Organisation for Economic Co-operation and Development Nuclear Energy Agency) (2014) Radioactive Waste Management and Decommissioning Working Group. Organisation for Economic Co-operation and Development Nuclear Energy Agency, Issy-lesMoulineaux, France. See http://www.oecd-nea.org/rwm/ (accessed 26/02/2015).

Ojovan MI and Lee WE (2013) An Introduction to Nuclear Waste Immobilisation, 2nd edn. Elsevier, Oxford, UK. ONR (Office for Nuclear Regulation) (2014) Office for Nuclear Regulation: Geological Disposal. Office for Nuclear Regulation, Bootle, UK. See http://www.onr.org.uk/ geodisposal.htm (accessed 26/02/2015).

Planning Act 2008 (2008) Elizabeth II. Chapter 29.

Her Majesty's Stationery Office, London, UK.

The Scottish Government (2011) Scotland's Higher Activity Radioactive Waste Policy. The Scottish Government, Edinburgh, UK.

West Cumbria MRWS (2012) http://www.westcumbriamrws.org. uk/ (accessed 26/02/2015).

\section{WHAT DO YOU THINK?}

To discuss this paper, please email up to 500 words to the editor at journals@ice.org.uk. Your contribution will be forwarded to the author(s) for a reply and, if considered appropriate by the editorial panel, will be published as discussion in a future issue of the journal.

Proceedings journals rely entirely on contributions sent in by civil engineering professionals, academics and students. Papers should be 2000-5000 words long (briefing papers should be 1000-2000 words long), with adequate illustrations and references. You can submit your paper online via www.icevirtuallibrary.com/content/journals, where you will also find detailed author guidelines. 